\title{
COVID-19: THE UNPRECEDENTED PHENOMENON OF TWENTY FIRST CENTURY UNBELIEVABLE BUT REALITY
}

\author{
Dr. B.S. Parimal \\ Ms. Kavita Gupta
}

\section{ABSTRACT}

During COVID-19 Pandemic followed by locked down period, Mental health has emerged as one of the essential componential thrust area to be considered at individual level, community level, National level and International level. To improve mental health in the present scenario, promotion of prevention with coping up strategy is essential for better mental health functioning and Psychological well-being. This review introduces an overview and discusses the conceptual frameworks of Existential Counseling therapy to illustrate a direct relationship between the anxiety of the general and affected populations due to COVID-19 and their ability to maintain optimal mental health functioning in the face of prolonged quarantine period. Based on literatures to date, understanding of Existential psychology as a preventive counseling therapy for mental health with a macroscopic perspective might help to practice positive mental health promotion and anxiety prevention. This study aims to characterize Existential Counseling as an appropriate preventive intervention and therapy that can feasibly be delivered to aid in the alleviation of symptoms of anxiety caused due to COVID-19 Pandemic.

A narrative review was conducted given the wide range of relevant interventions with sufficient promising evidence to understand the conceptual framework ofExistential Counseling as preventivepsychotherapy in the present crisis of COVID-19 Pandemic.

Interventions provided for optimal Mental Health functioning during the COVID-19 Pandemic have an important role to play in promoting mental health, preventing the onset, and protecting those with Anxiety symptoms. The importance of Existential Counseling as a preventive Psychotherapybeing highlighted in the present study is the need of hour in present scenario that lays the foundation for further research. 
Keywords: Existential Counseling; COVID-19; Anxiety

\section{INTRODUCTION:}

COVID-19 has created many confusions in the minds of people around the world. Anxiety levels have shot up and has become a challenge for psychologists to deal with the serious mental health issues in a significant chunk of the population and could lead to new set of anxieties emergence during post Quarantine life. The entire world is at standstill and watching this terrible transition as mute spectator.

At this juncture in present scenario of corona virus pandemic, in lockdown situation in general and quarantine compulsion to individuals, People tend to get anxious and that often leads to depression. Anxiety arises from our personal need to survive, to preserve our being, and to assert our being. Compared to normal anxiety, neurotic anxiety is out of proportion to the situation. It can be paralyzing and can inhibit creativity. People are not aware of this anxiety as it is a disproportionate reaction to an objective threat where People subjectively react to it in terms of their psychological patterns and conflicts (Nigesh\&Saranya, 2017).

These are common complains have been observed in India.

1. Claustrophobia: It is a form of anxiety disorder in which an irrational fear of having no escape of being closed in.

2. Fear of Death

3. Feeling of meaninglessness of life

4. Sense of being isolated

5. Escapism from responsibility and blaming others

\section{EXISTENTIAL COUNSELLING:}

This is very much relevant and related to address mental health related issues at present since large population are facing from. Existential counseling is a meaning-centered therapythat is considered to be connected to the philosophical concepts of the theory where the client needs to understand, synthesize, and apply existential concepts within the context of their own worldviews (Peoples\&Helsel, 2013). Existential Counseling is grounded in the understanding that experience is subjective (Harris, 2001)."The goal of existential counseling is to help clients make-meaning of their lives" (Edger \& Meyer, 2010, p. 17). Viktor Frankl (1959/2006) after his survival of the war concentration camps, described MEANING as an everpresent construct in the world and proposed that suffering was the best vehicle for finding meaning (Nigesh \& Saranya, 2017).Existential counselling is considered a phenomenological 
approach to counselling and was developed as a reaction to the two other major models, Psychoanalysis and Behaviorism. Rollo May and Viktor Frankl probably are the best-known existential theorists.

The function of this therapy is not to do away with all anxiety but rather to help clients confront anxiety so as to deal with specific fears of death due to pandemic crisis. The fear of death is the primary reservoir of anxiety that leads to use defense mechanisms. Ultimately, dealing effectively with Ultimate Concerns of Existentialism become sources of resolution of anxiety, conflicts and mental health issues.

Existential counselling is best described as Philosophical approach to counselling. "The existential approach helps people who are isolated, alienated, and not finding meaning in life to deal with their ANXIETY by enabling them to find meaning and purpose in life and to maintain their identity". Existential counselling focuses on the importance of anxiety, freedom, meaning, death, isolation and responsibility.

\section{ULTIMATE CONCERNS OF EXISTENCE:}

"The reality of death is important in Psychotherapy in two distinct ways: death awareness may act as a 'boundary situation'and instigate a radical shift in life perspective; and death is a primary source of anxiety".

--Irvin Yalom

Existential counselling is based on a model of psychopathology which posits that anxiety and its maladaptive consequences are responses to these four ultimate concerns. It is the awareness of these ultimate concerns that lead to anxiety. And accept them with reality and healthy attitude and transform them with positivity and determination will lead to the state of stability and healthy mind.

KEY CONCEPTS of existential counselling and its applications to resolve mental health issues:

Existential counsellors view the client as an existing immediate person, not as a composite of drives, archetypes and conditioning. Humans in this world are in a constant state of transition, evolving and becoming and have a capacity for self-awareness in making decisions and making change. So, in this situation of pandemic to be HERE and NOW needs constant practice without being overwhelmed for future uncertainty. 
Existentialism is based on the belief in ULTIMATE CONCERNS OF EXISTENCE and the anxiety resulting from awareness of these concerns and obsessions. This theory of counselling believes that a human's basic conflict is not due to suppressed instinctual drives or to significant adults in his or her early life or outside world's influence, rather, Conflicts, anxieties are caused by the individual and ultimate concerns of existence. Until and unless human beings change their belief system which are root cause of mental health issues, they can't resolve conflicts. Yalom identified FOUR ultimate concerns of existence as Death, Freedom, Isolation and Meaninglessness.

1. DEATH:According to existential counselling, death plays a major role in our internal experience and is a source of anxiety. Yalom (1974) states that a good working rule for clinicians is 'death anxiety is inversely proportional to life satisfaction'(Yalom, 1980) (Nigesh \& Saranya, 2017). At present in pandemic period the thought of death, specifically the victims of Corona virus have developed the obsession of death. A question is very common: "Would be I survived or existed?"

The terror of death is of such magnitude that a considerable portion of one's life energy is consumed in the denial of death. Thought of death is a primary source of anxiety and can result in psychopathology.

2. FREEDOM:The concept of freedom in existential counselling is associated with the concept of responsibility. To be aware of responsibility is to be aware of creating one's own self. We develop capacity to mould ourselves. For a client who will not accept such responsibility and persists blaming others feels constantly insecure.

At present, Common complain after going through social media, "Who is responsible for this?" "Blame-game... But instead of blaming others how do you perceive the situation.? Determines your happiness.

Existential theory assumes that nothing in the world has significance except by virtue of your own creation. There is no grand design in the universe, it is the individual alone who is the creator of his or her existence. People are free to choose alternatives and shape their Destinies. Other aspect is that people are aware about their roles and responsibilities but don't have willingness to change. Thus, freedom consists of responsibility and will.

3. ISOLATION: Existential isolation is a term meaning that no matter how closely we feel to another person, each of us enters existence alone. It refers to the unbridgeable gulf between oneself and any other person as well as, separation between the individual and 
the world. An individual never can fully share his or her consciousness with another person. And at this juncture, social distancing is not the real problem of anxiety and restlessness but individual has been so much conditioned with EMOTIONAL DISTANCING, that now it is the need of the hour to be closed with loved ones but it takes a long time to unlearn old life styles. Therefore, to transform individualistic into collectivistic has become a source of anxiety.

4. MEANINGLESSNESS: The fourth ultimate concern is meaninglessness. In depression causing situation, Common feeling is hopelessness. In this adverse situation, the whole world is mute for many unanswered questions e.g.

"What is the meaning of life?"

"What do we live for?"

These questions become instrumental in creating anxiety. Carl Jung believed that meaninglessness inhibited fullness of life and therefore was equivalent to illness.

The RECOGNITION of death can play a major role in counselling. Awareness and acceptance of death can help individuals to embrace life more FULLY and CREATIVELY. In addition to fully embracing life, it gives individuals many benefits, ordinarily individuals focus on what they don't have and what they can't do. But awareness of death could make them enjoy the things what they have and what they can do. After healthy recognition of death, people could also be grateful for the many things.

\section{ANALYSIS:}

Existential counselling does not seek to cure or explain. But major focus is on precautionary and preventive measures. The consequences of corona crisis are unpredictable whether Emotionally, Socially, Mentally, Physically and Economically. So, it is a challenging situation for counsellors to deal with mental health issues. Existential counselling seeks to explore, describe and clarify so as to try to understand the human predicament. Existential counsellors assist clients in seeing ways in which they are not fully present in the rest of their lives with extreme level of Anxiety.

At present, Common existential problems being experienced by people are insecurity of personal growth in future, facing death, stage of life crisis, loneliness, Meaninglessness, loss and identity problems. Other conditions associated with defenses to confrontations with 
existential concerns include depression, addictions, obsessions, Exhaustion of isolation, Communication in relationship.

The goal of existential therapy is not to free clients from anxiety, but rather to help them accept, bear, and live constructively with anxiety. From the narrative review, it could be depicted that the Process and Goals of Existential Counselling in Corona Catastrophic should be followed:

\section{Goals:}

1. The lack of guarantees in life is precisely what generates anxiety. This therapy helps clients to face the anxiety and make them accept the reality.

2.Existential counselling encourages clients to accept their personal responsibility rather being dependent on others.

3. Counselors will challenge clients to focus on how they created their own circumstances or situations rather than placing blame to others.

4.Individuals who are unaware of the reality of death typically postpone living with happiness in present and may be obsessed by past events or fearful of anticipated future events. This counselling lead them " HERE AND NOW situation with blissful state of mind.

5.In this pandemic period, a fear of being alone, that is, Auto Phobia is a very common behavior in people. Quarantine seems mental prison for them. And avoiding pain of loneliness which may resort to a variety of behaviors like substance abuse, compulsive behaviorsworkaholism etc. specially in case of people having single status.

In counselling, clients may confront isolation, learn to be alone, develop the attitude to perceive the State of Solitude as a source of happiness and learn many coping skills to deal with inevitable crisis circumstances.

6.The major benefit of this counselling is finding meaning, reason, vision and mission of living life by engagement in helping and caring for others, interests in ideas and projects, searching, creating and building.

\section{MEANIGFULNESS:}

One third case were not suffering from any clinically definable neuroses... But Rather from the senseless and aimless of their lives (Yalom) Corona effect has created stagnation in people's 
mind to think positively and due to these mental blockages, they don't find reason to go ahead in life journey. Finding meaning to live, relieves the anxiety and maintains stability of mind. Enhancement of Spiritual Quotient is only the solution for facing such inevitable, uncomfortable and uncontrollable situation.

However,Existential Psychotherapy considers 'Growth enhancing' psychotherapy with a phenomenological approach rather than ICD 10 or DSM diagnosis as a necessary precondition for psychotherapy (Nigesh \& Saranya, 2017)

\section{CONCLUSION:}

After gaining insight into the issues of isolation, meaninglessness, fear of death and responsibility, clients are encouraged to take change of how they now choose to be in their world. Further counsellors also encourage clients to take actions based on the insights that they have learned in counselling. Counsellors help clients to redefine themselves and develop greater genuine contact with life. Clients are encouraged to confront their mental health problems and develop more effective means of coping. Individuals should focus on the true essence of human life.

Finally, through self-exploration and insight, the client becomes aware of the ultimate concerns of existence and his or her freedom in choosing to make changes and live a more purposeful life in Crisis of life.

It could thus be analyzed that applying the existential approach based on individualistic and collectivist pattern is to decrease symptoms of Anxiety accompanied by negative attitude towards life on breakout of Pandemic Covid-19, thereby leading to inappropriate consequences due to under pressure of psychological problems in the result of many tensions, therefore it is suggested that the consultative Existential Psychotherapyshould be considered to decrease negative and unwanted psychological impacts of Covid-19 Pandemic. 


\section{REFERENCES}

Cohn, H.W. (1997). Existential thought and therapeutic practice: An introduction to existential psychotherapy. London: Sage.

Corey, G. (1996). Theory and practice of counseling and psychotherapy ( $5^{\text {th }}$ ed.). Pacific Grove, CA: Brooks/Cole.

Deurzen-Smith, E. (1988). Existential counselling in practice. Newbury Park, CA: Sage.

Deurzen-Smith, E. (1997). Everyday mysteries: Existential dimensions of psychotherapy. London: Routledge.

Don, C., Locke, Jane Myers, Edwin L. Herr. (2001). The Handbook of Counseling. SAGE Publications. ISBN: 1452262594.

Du Plessis, Guy. (2019). An Existential Perspective on Addiction Treatment: A Logic-Based Therapy Case Study. International Journal of Philosophical Practice, Volume 5, Number 1. Winter 2019. Available at SSRN: https://ssrn.com/abstract=3350606 or http://dx.doi.org/10.2139/ssrn.3350606

Frankl, V.E. (1963). Man's search for meaning. Boston: Beacon.

Frankl, V.E. (1969). The will to meaning: Foundations and applications of logotherapy. New York: New American Library.

Frankl, V.E. (1984). Man's search for meaning ( $3^{\text {rd }}$ ed.). New York: Washington Square Press.

Heidegger, M. (1962). Being and time. New York: Harper \& Row.

May, R. (1950). The meaning of anxiety. New York: Ronald Press.

May, R. (1953). Man's search for himself. New York: Norton.

May, R. (Ed.). (1961). Existential psychology. New York: Random House.

May, R. (1969). Love and will. New York: Norton.

Nigesh K, \& Saranya T. S. (2017). Existential Therapies: Theoretical basis, Process, Application and Empirical Evidences. International Journal of Education and Psychological 
Research (IJEPR), Volume 6, Issue 2, 112-120. Available at: http://ijepr.org/panels/admin/papers/ij25.pdf

Peoples, K., \& Helsel, S. (2013). Bridging the Gap Between Theory and Practice With Film: How to Use Fight Club to Teach Existential Counseling Theory and Techniques. SAGE Open, 3, 1-7. doi:10.1177/2158244013497028.

Dr. B.S. Parimal

Assistant Professor

Department of Psychology,

Faculty of Education and Psychology,

The Maharaja Sayajirao University of Baroda, Vadodara, Gujarat

Email: drbsparimal@gmail.com

\&

Ms. Kavita Gupta

Assistant Professor

Department of Psychology,

Faculty of Education and Psychology,

The Maharaja Sayajirao University of Baroda, Vadodara, Gujarat

Email: 16kavitagupta@gmail.com 